${ }^{10}$ Adams EF, Brajkovich IE, Mashiter K. Growth hormone and prolactin secretion by dispersed cell cultures of human pituitary adenomas: long term effects of hydrocortisone, estradiol, insulin, $3^{\prime}, 5^{\prime}, 3^{\prime}$ triiodothyronine and thyroxine. 7 Clin Endocrinol Metab 1981;53:381-6.

1 Sterling RE, Nagao RR. Evaluation of the glucose analyser. Clin Chem $1969 ; 15: 801-2$.

12 Merrifield RB. Solid phase synthesis. Fournal of the American Chemistry Society 1963;85:2149-56.

13 Brazeau P, Ling N, Bohlen P, Esch F, Ying S, Guilleman R. Growth hormone releasing factor, somatocrinin, releases pituitary growth hormone in vitro. Proc Natl Acad Sci USA 1982;79:7909-13.
${ }^{14}$ Wehrenberg WB, Ling N, Brazeau P, et al. Somatocrinin, growth hormone releasing factor, stimulates secretion of growth hormone in anesthetized rats. Biochem Biophys Res Commun 1982;109:382-7.

${ }^{15}$ Brazeau P, Ling N, Esch F, Bahlen P, Mougin J, Guilleman R. Somatocrinin (growth hormone releasing factor) in vitro bioactivity; $\mathrm{Ca}^{++}$ involvement, cAMP mediated action and additivity of effect with PGE $^{2}$. Biochem Biophys Res Commun 1982;109:588-94.

\title{
Evidence for a hypothalamic disturbance in cyclical oedema
}

\author{
J B YOUNG， A M BROWNJOHN，C CHAPMAN， M R LEE
}

\begin{abstract}
Fourteen women with cyclical oedema and six healthy female controls were investigated by use of a test in which thyrotrophin releasing hormone and luteinising hormone releasing hormone were given. Significant differences in the responses of prolactin, luteinising hormone, and follicle stimulating hormone were observed in the patients.

These findings suggest that there may be a hitherto unrecognised hypothalamic defect in cyclical oedema that may account for some of the previously unexplained clinical features and lead to a more rational therapeutic approach in the management of the disorder.
\end{abstract}

\section{Introduction}

Idiopathic or cyclical oedema is a disorder almost exclusively of women, characterised by intermittent bouts of generalised swelling aggravated by standing. Other recognised causes of oedema must first be excluded, and the diagnosis then rests on the typical symptom complex and whether an excessive diurnal weight gain occurs. ${ }^{1-3}$ The cause of the condition is uncertain. Previous studies have suggested that women with cyclical oedema have chronic hypovolaemia and that standing induces a decrease in urine flow and urinary excretion of sodium, ${ }^{145}$ but the mechanism for this hypovolaemia is disputed.

Attention has been drawn to the emotional lability exhibited by women with cyclical oedema..$^{16-8}$ So prominent is this feature that Thorn suggested that it should form a part of the clinical symptom complex for establishing the diagnosis. ${ }^{3}$ The major depressive disorders are often associated with a disturbance of the hypothalamic-pituitary axis, ${ }^{9-12}$ and in view of the psychological and emotional problems that accompany cyclical oedema we carried out a study to investigate hypothalamic function by means of a combined thyrotrophin

Renal Unit, General Infirmary, Leeds LS1 3EX

J B YOUNG, MRCP, registrar

A M BROWNJOHN, MRCP, consultant physician

Department of Nuclear Medicine, General Infirmary

C CHAPMAN, PHD, principal biochemist

Department of Medicine, General Infirmary

M R LEE, FRCP, consultant physician

Correspondence to: Dr J B Young. releasing hormone and luteinising hormone releasing hormone test in 14 women with the disorder.

\section{Subjects and methods}

Women complaining of generalised swelling and with a documented diurnal weight gain in excess of $1.4 \mathrm{~kg}$ were considered to have cyclical oedema provided that other causes of oedema had been excluded by physical examination and biochemical investigation. We studied 14 patients (mean age $35 \pm$ SEM 3.0 years and mean weight $67+3.5 \mathrm{~kg}$ ) and six normal female volunteers (mean age $32 \pm 2.5$ years and mean weight $61.5 \pm 2.0 \mathrm{~kg}$ ). No subject in either group was taking an oral contraceptive pill, but most patients had previously received diuretics. Whenever possible diuretic treatment was slowly withdrawn so that at the time of the study eight patients had stopped taking diuretics a minimum of three months previously, three were receiving them, and three had never received them. Informed consent was obtained, and the study was approved by the hospital research ethics committee.

All subjects were studied during the preovulatory phase of the menstrual cycle as confirmed by plasma oestradiol and progesterone concentrations. The study was conducted by the same investigator with the subjects recumbent after an overnight stay in hospital. A light standard breakfast was given at 0800 and an intravenous cannula inserted at 0900 . At 1000 basal blood samples were taken for measurement of concentrations of oestradiol, progesterone, prolactin, testosterone, leuteinising hormone, follicle stimulating hormone, and thyroid stimulating hormone. Consecutive injections of $100 \mu \mathrm{g}$ luteinising hormone releasing hormone (Gonadorelin, Ayerst) and $200 \mu \mathrm{g}$ thyrotrophin releasing hormone (Roche) were then given and blood samples taken at $20,40,60,90,120$, and 150 minutes for estimation of plasma concentrations of prolactin, luteinising hormone, follicle stimulating hormone, and thyroid stimulating hormone by radioimmunoassay. Statistical analysis of the results was performed using Student's $t$ test for unpaired observations.

\section{Results}

Prolactin (table)-The mean prolactin concentrations in the patients were significantly greater than those in the controls at 20 and 40 minutes $(p<0.025)$ and at 60 and 90 minutes $(p<0.05)$. Basal prolactin concentrations were normal in the patients except in one with galactorrhoea, in whom they were 1165 and $1041 \mathrm{mU} / 1$ at 0 and 150 minutes, respectively.

Luteinising hormone (table)-The mean response of luteinising hormone was more pronounced in the patients than the controls; at $40,60,120$, and 150 minutes these differences were significant $(\mathrm{p}<0.05)$.

Follicle stimulating hormone (table) showed a significantly different response in the patients compared with the controls at 120 and 150 minutes $(\mathrm{p}<0.05)$.

Thyroid stimulating hormone-The mean response of thyroid stimulating hormone was not significantly different between the 
patients and controls. In two patients, however, exaggerated responses were observed at 20 minutes, with concentrations of 41 and $39 \mathrm{mU} / 1$ compared with a mean control value of $16 \cdot 25 \pm 2 \cdot 2 \mathrm{mU} / 1$ at this time.

Oestradiol and progesterone concentrations did not differ significantly between the patients and controls, and there was no correlation between oestradiol concentrations and peak luteinising hormone or prolactin responses in individual patients.

Testosterone-Basal plasma testosterone concentrations were normal in all patients (mean $1 \cdot 2 \pm 0.05 \mathrm{nmol} / 1(0.3 \pm 0.01 \mathrm{ng} / \mathrm{ml})$ ) and controls (mean $1.3 \pm 0.09 \mathrm{nmol} / 1(0.4 \pm 0.03 \mathrm{ng} / \mathrm{ml})$ ). responses have been described in the major depressive disorders and have been attributed to a disturbance of neurotransmitter function in the hypothalamus. ${ }^{912}$ These common features suggest an analogous disturbance of hypothalamic function in $\widehat{\widehat{C}}$ cyclical oedema and might explain the psychological component of the disorder.

Attempts have been made to distinguish various forms of $\stackrel{\text { }}{\mathbb{D}}$ cyclical oedema to explain the variations in clinical findings and $m$ investigations ${ }^{1}$ and in response to treatment. ${ }^{19}$ Patients with

Responses of prolactin to $200 \mu \mathrm{g}$ thyrotrophin releasing hormone and of luteinising hormone and follicle stimulating hormone to $100 \mu g$ luteinising hormone releasing hormone in six controls and 14 patients with cyclical oedema (results expressed as means 1 $S E M)$

\begin{tabular}{|c|c|c|c|c|c|c|c|}
\hline Minutes after injection: & 0 & 20 & 40 & 60 & 90 & 120 & 150 \\
\hline $\begin{array}{l}\text { Prolactin }(\mathrm{mU} / 1): \\
\quad \text { Controls } \\
\text { Patients } \\
\text { p }\end{array}$ & $\begin{array}{c}226 \pm 22 \\
367 \pm 79 \\
\text { NS }\end{array}$ & $\begin{array}{c}772 \pm 73 \\
1660 \pm 247 \\
<0.025\end{array}$ & $\begin{aligned} & 618 \pm 42 \\
& 1264 \pm 163 \\
&<0.025\end{aligned}$ & $\begin{array}{c}483 \pm 41 \\
875 \pm 118 \\
<0.05\end{array}$ & $\begin{array}{c}347 \pm 35 \\
617 \pm 91 \\
<0.05\end{array}$ & $\begin{array}{c}287 \pm 23 \\
490 \pm 83 \\
\text { NS }\end{array}$ & $\begin{array}{c}268+16 \\
394 \pm 62 \\
\text { NS }\end{array}$ \\
\hline $\begin{array}{l}\text { Luteinising hormone (IU/1): } \\
\text { Controls } \\
\text { Patients } \\
\text { p }\end{array}$ & $\begin{array}{c}4 \cdot 0 \pm 0 \cdot 4 \\
9 \cdot 6 \pm 2 \cdot 5 \\
\text { NS }\end{array}$ & $\begin{array}{c}16 \cdot 2 \pm 2 \cdot 3 \\
39 \pm 9 \\
\mathrm{NS}\end{array}$ & $\begin{array}{c}18 \cdot 7 \pm 2 \cdot 5 \\
51 \pm 12 \\
<0.05\end{array}$ & $\begin{array}{c}16 \cdot 8 \pm 2 \cdot 2 \\
53 \cdot 0 \pm 12 \cdot 5 \\
<0.05\end{array}$ & $\begin{array}{c}14.5 \pm 1 \cdot 8 \\
52 \pm 14 \\
\mathrm{NS}\end{array}$ & $\begin{array}{c}13 \cdot 2+1 \cdot 3 \\
51+13 \\
<0.05\end{array}$ & $\begin{array}{c}12.0-1.3 \\
46-12 \\
<0.05\end{array}$ \\
\hline $\begin{array}{l}\text { Follicle stimulating hormone (IU/l): } \\
\text { Controls } \\
\text { Patients } \\
\text { p }\end{array}$ & $\begin{array}{c}5 \cdot 2 \pm 0 \cdot 3 \\
7 \cdot 6 \pm 2 \cdot 2 \\
\text { NS }\end{array}$ & $\begin{array}{c}8 \cdot 0+0.5 \\
11 \cdot 2+2 \cdot 3 \\
\mathrm{NS}\end{array}$ & $\begin{array}{c}10 \cdot 2 \pm 0 \cdot 5 \\
15 \cdot 1 \pm 3 \cdot 7 \\
\mathrm{NS}\end{array}$ & $\begin{array}{c}10 \cdot 2 \\
17 \cdot 2 \cdot 6 \\
\mathrm{NS}\end{array}$ & 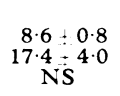 & $\begin{array}{c}8 \cdot 1=0.5 \\
16 \cdot 0 \\
<0.05\end{array}$ & $\begin{array}{c}7 \cdot 7+0 \cdot 4 \\
15 \cdot 5 \\
<0.05\end{array}$ \\
\hline
\end{tabular}

\section{Discussion}

The cause of idiopathic or cyclical oedema is unresolved. One feature of the condition is the worsening of the oedema during standing, and several studies have shown that women with cyclical oedema respond to such change in posture as though they had chronic hypovolaemia, with compensatory renal sodium and water retention and a reduction in the rate of flow of urine. ${ }^{145}$ The mechanism for this hypovolaemia is not clear. There may be a defect in the capillary vascular bed, due either to the capillary endothelium being unduly "leaky" or to abnormal dilatation of the precapillary sphincters producing a large increase in the capillary surface area available for fluid transudation. ${ }^{6}$ Alternatively, diuretic abuse has been proposed as the sole factor producing hypovolaemia, ${ }^{13}{ }^{14}$ while others have argued that diuretics merely aggravate pre-existing hypovolaemia. ${ }^{15-18}$

The psychological and emotional problems exhibited by patients with cyclical oedema contribute to the difficult and unsatisfactory management of the condition. Most of the patients we studied showed these features and admitted to increased irritability and sharp temper during episodes of swelling. These psychological disturbances cannot be explained by previously proposed mechanisms for the disorder. In several patients there was a considerable disparity between the subjective sensation of bloatedness and the degree of demonstrable swelling or weight gain. One explanation for this might be the rapid transfer of fluid across vascular endothelium without net gain in body weight. ${ }^{14}$ This sensation was so prominent in some patients, however, that it suggested a disturbance of body image akin to that seen in anorexia nervosa, a condition in which a hypothalamic abnormality has been suggested and which is also predominantly a disorder of women.

This study showed that in patients with cyclical oedema the responses of prolactin, luteinising hormone, and follicle stimulating hormone to thyrotrophin releasing hormone and luteinising hormone releasing hormone are significantly different from normal, suggesting abnormal regulation of these hormones due to a disturbance of the hypothalamic-pituitary axis. A primary pituitary lesion seems unlikely as, except in one patient with a raised basal prolactin concentration, basal hormone concentrations were normal and in no patient was there clinical or radiological evidence of a pituitary tumour. Similar abnormal subclinical hypothyroidism may present with features similar $\underset{\infty}{N}$ to those of cyclical oedema, and it is important to identify these $>$ patients as they may respond to treatment with thyroxine ${ }^{20}$ or triiodothyronine (W J Jeffcoate and R J E Davis, personal $\vec{\theta}$ communication). Our patients had normal serum thyroxine $\infty$ and triiodothyronine concentrations and a normal free thyroxine index, but in two cases an exaggerated response of thyroid stimulating hormone was observed, suggesting subclinical hypothyroidism. One of these patients was treated with $200 \mu \mathrm{g}$ thyroxine daily for two months. Her pitting oedema did not improve, and a further test using thyrotrophin releasing $\mathscr{\Phi}$ hormone and luteinising releasing hormone showed suppression $\overrightarrow{\vec{F}}$ of thyroid stimulating hormone, but prolactin and luteinising 3 hormone responses remained abnormal. An exaggerated re- $\bar{T}$ sponse of luteinising hormone due to a proposed primary hypothalamic abnormality has also been found in the polycystic ovarian syndrome, ${ }^{21}$ some clinical features of which (obesity and oligomenorrhoea) may overlap with those of cyclical oedema. Some of our patients were obese and others had oligomenorrhoea, 3 but there were no other features to suggest the polycystic ovarian syndrome, and plasma testosterone concentrations were $\frac{\rho}{3}$ normal in all patients.

If a hypothalamic disturbance does exist in cyclical oedema then there must be a link between this central defect and a $N$ peripheral mechanism for the formation of oedema. We found $D$ an abnormality in prolactin regulation, and prolactin has been shown to cause isotonic movement of water from the $N$ intracellular to the extracellular fluid compartments ${ }^{22}$; this might explain some of the peripheral features of cyclical oedema. $O$ Basal prolactin concentrations were abnormal in two previously reported cases of cyclical oedema. ${ }^{19}{ }^{23}$ In both cases hyper-? prolactinaemia was present, associated in one case with galactorrhoea and amenorrhoea ${ }^{23}$; and both patients became free 0 of oedema in response to treatment with bromocriptine, a dopamine agonist that inhibits secretion of prolactin. Oedema is not, however, a feature of hyperprolactinaemia associated with $\frac{?}{\Phi}$ prolactinomas and cannot therefore be solely due to excessive $\frac{\varrho}{\sigma}$ secretion of prolactin. The oedema might be explained by a more generalised hypothalamic disturbance including an abnormality in the release of natriuretic factor. This would be in keeping with previous observations suggesting altered secretion of natriuretic factor in cyclical oedema. ${ }^{24}$

The abnormalities of secretion of prolactin, follicle stimulating 
hormone, and luteinising hormone that we found support the concept that cyclical oedema is due to a generalised hypothalamic disturbance producing the somatic and psychological features of the condition. Alternatively, there may be an undefined peripheral factor with secondary hormonal changes that are only markers for the condition. Once an abnormality in the hypothalamic-pituitary axis has been identified the effect of diuretics, dopamine agonists, and centrally acting antidepressant drugs on this abnormality should be determined in the hope that a more effective treatment may be developed. In addition, the test using thyrotrophin releasing hormone and luteinising hormone releasing hormone may enable a more precise and objective diagnosis to be made in this common and distressing disorder.

We are grateful to Mrs J Holt, Mr M Hushein, Mr P Clarkson, and Miss $\mathrm{C}$ Jinks for performing the radioimmunoassays in this study and to Miss B Hildreth for her dietetic advice. We also thank the staff of the division of steroid endocrinology for the assays of the steroid hormones.

\section{References}

${ }^{1}$ Streeton DHP. Idiopathic oedema: pathogenesis, clinical features and treatment. Metabolism 1978;27:353-83.

2 Anonymous. Idiopathic oedema of women [Editorial]. $\mathrm{Br} M e d \mathcal{F}_{1976}$;i: 979.

3 Thorn GW. Approach to the patient with "idiopathic oedema" or "periodic swelling." $\mathcal{F} A M A$ 1968;206:333-8.

${ }^{4}$ Kuchel O, Cuche JL, Buu NT, et al. Catecholamine excretion in "idiopathic" oedema: decreased dopamine secretion, a pathogenic factor? f Clin Endocrinol Metab 1977;44:639-46.

${ }^{5}$ Ferris TF, Chonko AM, Williams JS, Reineck HJ, Stein JH. Studies of the mechanisms of sodium retention in idiopathic oedema. Trans Assoc Am Physicians 1973;86:310-1.
${ }^{6}$ Edwards OM, Bayliss RIS. Idiopathic oedema of women. $Q \mathcal{F} \mathrm{Med}$ $1976 ; 177: 125-44$.

${ }^{7}$ McKendry JBR, McClaren MC, Bloom GM. Idiopathic intermittent oedema of women with interpersonal conflict. Amsterdam: Exerpta Medica, 1966:59-63. (International Congress Series No 134.)

${ }^{8}$ Gordon ES, Graham DT. Metabolic oedema. F Lab Clin Med 1959;54: 818-9.

${ }^{9}$ Ettigi PG, Brown GM. Psychoneuroendocrinology of affective disorder: an overview. $A m \mathcal{F}$ Psychol 1977;134:493-501.

${ }_{11}$ Anonymous. The new psychiatry [Editorial]. Br Med $\mathcal{F} 1981 ; 283: 513$.

${ }^{11}$ Kiyoshi M, Tanimoto K, Yamaguchi N, Iwaski Y, Chihara K, Fujita T. Increased prolactin response to TRH in mania. $N$ Engl $\mathcal{f}$ Med 1979 25:1400.

${ }^{12}$ Horrobin DF, Mtabaji JP, Karmali RA, Manku MS, Nassar BA. Prolactin and mental illness. Postgrad Med $\mathcal{f}$ 1976;52:79-85.

13 MacGregor GA, Markandu ND, Roulston JE, Jones JC, de Wardener HE. Is "idiopathic" oedema idiopathic ? Lancet 1979;i:397-400.

14 de Wardener HE. Idiopathic oedema: role of diuretic abuse. Kidney Int $1981 ; 19: 881-92$

15 Streeten DHP. Idiopathic oedema. Lancet 1979;i :775-6.

${ }_{16}$ Dunnigan MG, Lawrence JR. Idiopathic oedema. Lancet 1979;i:776-7.

17 Edwards OM, Dent RG. Idiopathic oedema. Lancet 1979; ; 1188.

18 Lagrue G, Behar A, Baillet J. Idiopathic oedema. Lancet 1979;i:1188.

${ }^{19}$ Edwards CRW, Besser GM, Thorner MO. Bromocriptine responsive form of idiopathic oedema. Lancet 1979;ii:94.

${ }^{20}$ Al-Khader AA, Aber GM. The relationship between the "idiopathic oedema syndrome" and sub-clinical hypothyroidism. Clin Endocrinol $1979 ; 10: 271-9$.

${ }^{21}$ Wortsman J, Singh KB, Murray J. Evidence for the hypothalamic origin of the polycystic ovarian syndrome. Obstet Gynecol 1981;58:137-41.

${ }^{22}$ Mills DE, Buckman MT, Peake GT. Effects of prolactin administration and suppression on blood pressure and body fluid compartments in the rat. Endocrinology $1981 ; 109: 1590-6$.

${ }^{23}$ Evered DC, Horrobin DF, Vice PA, Cole EN, Nassar BA. Idiopathic oedema and prolactin. Proceedings of the Royal Society of Medicine $1975 ; 69: 427-8$.

${ }^{24}$ Favre H, Mach RS. Etude du "facteur natriurétique" chez des malades atteints d'oedèmes idiopathiques. Schweiz Med Wochenschr 1980;110: $1107-11$.

(Accepted 24 March 1983)

\title{
Serum pancreatic lipase activity in cystic fibrosis
}

\author{
D JUNGLEE, A PENKETH, A KATRAK, M E HODSON, J C BATTEN, P DANDONA
}

\begin{abstract}
Patients with cystic fibrosis have been found to have abnormal serum concentrations of immunoreactive trypsin and abnormal activities of pancreatic isoamylase. A study was undertaken to discover whether activity of pancreatic lipase is also altered in cystic fibrosis. Serum from 23 patients with cystic fibrosis was assayed for immunoreactive trypsin and pancreatic lipase. Median serum pancreatic lipase activity was significantly lower in patients with cystic fibrosis than in controls,
\end{abstract}

Metabolic Unit, Department of Chemical Pathology, Royal Free Hospital, London NW3 2QG

D JUNGLEE, MSC, FIMLS, medical laboratory scientific officer

A KATRAK, BSC, FIMLS, medical laboratory scientific officer

P DANDONA, MRCP, DPHIL, director of metabolic unit and senior lecturer in chemical pathology

Brompton Hospital, London SW1

A PENKETH, MRCP, research registrar

$M$ E HODSON, DM, MRCP, senior lecturer and consultant physician

J C BATTEN, MD, FRCP, consultant physician

Correspondence to: Dr P Dandona. as was immunoreactive trypsin concentration $(p<0.0001)$. Some patients had supranormal lipase concentrations but these were not always associated with absence of malabsorption.

Serum pancreatic lipase activity is considerably changed in cystic fibrosis.

\section{Introduction}

Patients with cystic fibrosis have been found to have abnormal serum concentrations of immunoreactive trypsin ${ }^{12}$ and abnormal activities of pancreatic isoamylase. ${ }^{3}$ There have, however, been no observations on pancreatic lipase activity in sera of these patients. We therefore undertook a study to examine whether the activity of this enzyme is altered in cystic fibrosis.

\section{Patients and methods}

Blood samples were collected from 23 patients with known cystic fibrosis (age range 12 to 38 years) with sweat sodium and chloride concentrations greater than $70 \mathrm{mmol}(\mathrm{mEq}) / \mathrm{l}$. The serum was separated and stored at $-20^{\circ} \mathrm{C}$.

Serum was thawed on the day of the assay, and the assays for immunoreactive trypsin and pancreatic lipase were undertaken on 